and Physiotherapists. 17 projects have been submitted as presentations for the upcoming Irish Paediatric Association (IPA) Conference. In addition a further 10 projects are due for presentation at a variety of European Meetings in 2017, 1 project is now informing National UTI Guidelines and 1 project has been submitted for publication at a peer-reviewed Journal. In the year prior to the Research workshop initiative; 2 oral presentations and $9(\mathrm{P})$ presentations were accepted at the IPA Conference. The feedback to date is overwhelmingly positive with Junior Doctors reporting greater support, interest and involvement in research.

Conclusions The workshops continue and have expanded to include the General Paediatric Departments of Dublin's 2 other Children's Hospitals. The opening of Ireland's new National Paediatric Hospital in 2022 will provide great opportunities for further development of the Academic Department of General Paediatrics.

The goal is that this initiative will contribute to a structured template for further Research workshops across all Paediatric centres in Ireland and provide a collaborative Network for General Paediatric Research in the future.

\section{G187(P) SAFEGUARDING CHILDREN WHO DISPLAY SEXUALLY HARMFUL BEHAVIOUR- ARE WE UP TO SCRATCH? RESULTS FROM A MULTIAGENCY AUDIT}

${ }^{1} \mathrm{~K}$ Glenn, ${ }^{2} \mathrm{~A}$ Mott, ${ }^{3} \mathrm{~K}$ Gale. 'Paediatrics, Cardiff and Vale University Hospital Board, Cardiff, UK; ${ }^{2}$ Safeguarding Children, Public Health Wales, Cardiff, UK; ${ }^{3}$ Paediatrics, Cwm Taf Health Board, Merthyr Tydfil, UK

\subsection{6/archdischild-2018-rcpch. 182}

Background Children and young people who develop sexually harmful behaviour (SHB) have usually experienced abuse and neglect themselves. ${ }^{1}$ Multiagency procedures acknowledge that the perpetrators of $\mathrm{SHB}$ need active management to reduce the impact of on-going harm to themselves and others.

An LSCB audit in 2013 demonstrated that the needs of these children were not being recognised and procedures were not being followed.

Objectives Re-audit of management of alleged child perpetrators to establish whether guidance is being followed across 2 Local Authorities.

Methodology Children presenting as victims of sexual abuse during 2015 were identified where both victim and perpetrator were under 18. Cases analysed using the 2013 audit tool collecting data from health, children's services, police, Barnados, NSPCC and Youth Offending Services. Anonymised case histories were obtained from Children's Services to provide qualitative data.

Results Of 47 cases, there was an improvement in the number of strategy meetings/discussions with one LA increasing its numbers from $41 \%$ to $77 \%$. There was also an increase from $75 \%$ to $86 \%$ in the other LA. However, there were 6 children across both LA's that did not have a strategy meeting or a discussion. One LA proactively involved YOS in strategy meetings to develop multiagency plans to protect children and enable them to return to school. However not all children benefitted from multiagency planning, some children reoffended and there was limited involvement by specialist services.

Conclusion Re-audit demonstrated improvement compared to 2013, however, services are still failing these children. Case studies demonstrated their complex lives and background of adverse childhood experiences. These children, despite having the highest level of need can be the most challenging to help and engage. More should be done to meet the needs of this vulnerable group which may, in turn, help to transform the direction of their lives.

\section{REFERENCE}

1. Hackett S, Phillips J, Masson H, Balfe M. Individual, family and abuse characteristics of 700 British child and adolescent sexual abusers. Child Abuse Review 2013;22(4):232-245.

\section{G188(P) A SURVEY OF COMMUNITY PAEDIATRIC TRAINEES CAMHS EXPERIENCE}

${ }^{1} E$ Payne, ${ }^{2} \mathrm{G}$ Salmon, ${ }^{3} \mathrm{~N}$ John. ${ }^{1}$ Community Child Health, Wales Deanery, Cardiff, UK; ${ }^{2}$ Child and Adolescent Mental Health Services (CAMHS), Cwm Taf University Health Board, Swansea, UK; ${ }^{3}$ Community Child Health, Cardiff and Vale University Health Board, Cardiff, UK

\subsection{6/archdischild-2018-rcpch. 183}

Aim It is difficult for Level 3/GRID CCH (Community Child Health) trainees to obtain mental health competencies in the curriculum. With Community Paediatrics facing increasing mental health challenges due to stretched CAMHS (Child and Adolescent Mental Health Service) services, the aim of our project was to survey the educational value of CAMHS posts for $\mathrm{CCH}$ trainees and ask: Are training posts in CAMHS of benefit?'

Method Two surveys were hosted on Survey Monkey; one for $\mathrm{CCH}$ trainees who had completed a training post in CAMHS and a second for those who had not. The surveys were distributed UK-wide via the BACCH Trainee Group and Regional Coordinators.

Results $18 \mathrm{CCH}$ trainees who had not done CAMHS, and six who had, completed the survey. Four of the six CAMHS posts were split with community paediatrics. Feedback from these trainees suggested that this limited the educational value of the post. The two trainees who did a full-time CAMHS post rated their experience very highly and recommended the post. Trainees who had experienced CAMHS rated themselves as more confident at assessing for anxiety and depression and in risk-assessing for self-harm and suicide compared to trainees who had not. Average self-ratings for behaviour management, managing ADHD medication and recognising reactions to stress and bereavement were not clearly increased following the CAMHS posts.

Of the $18 \mathrm{CCH}$ trainees with no experience in CAMHS, $50 \%$ reported that they planned to do a post in CAMHS. Of those who did not, $71 \%$ stated it was due to a lack of provision and $28 \%$ stated they had no interest in doing so.

Conclusion Most $\mathrm{CCH}$ trainees in the survey wished to have training in CAMHS and those who have, rated the experience highly. The educational value is limited by split posts. It is, therefore, recommended that deaneries develop full-time training posts for $\mathrm{CCH}$ trainees.

\section{G189(P) CHILDREN WITH TRACHEOSTOMIES: THE IMPACT ON FAMILY LIFE}

IJ Collins, ${ }^{2} \mathrm{~K}$ Burns, ${ }^{3} \mathrm{M}$ McGinn. ${ }^{1}$ Paediatric Emergency Medicine, RBHSC, Belfast, UKi ${ }^{2}$ Clinical Psychology, RBHSC, Belfast, UK; ${ }^{3}$ Community Paediatrics, Belfast Trust, Belfast, UK

10.1136/archdischild-2018-rcpch.184 